
Micromachines and Applications

15-30APRIL 2021/ ONLINE

\title{
Lipid-based Nanoparticle Production in Micromixers
}

Dr. Vahé Nerguizian",*, Dr. Rubén López Salazar²

${ }^{1}$ École de technologie supérieure, 1100 Notre Dame West, Montreal, QC, Canada, $\mathrm{H} 3 \mathrm{C} 1 \mathrm{~K} 3$

${ }^{2}$ McGill University, Research Institute of the McGill University Health Centre, 1001 Decarie Blvd, Montreal, Quebec H4A 3J1

* Corresponding author: vahe.nerguizian@etsmtl.ça 


\section{Abstract:}

Lipid-based nanoparticles have demonstrated to be a versatile vehicle for drugs, genetic material, and labels. These particles are often made of biocompatible and biodegradable materials, enabling a safe interaction with biological systems. The importance of this type of delivery vehicle has been shown recently, as the two leading vaccines are based on lipid-nanoparticles encapsulating mRNA.

Passive micromixers produce lipid nanoparticles in a reproducible and controllable way. However, micromixers suffered at the beginning of low production rate, and complicated designs which were difficult to produce and prone to clogging. In recent years, the exploration of different mixing strategies based on the use of curvilinear paths to induce centripetal forces and vortex formation at high speeds as well as the increase of the microchannel cross-sectional area while keeping laminar flow regimes has led to designs capable of producing lipid-based nanoparticles on an industrial-scale.

However, there are still challenges in the field which include the removal or substitution of the organic solvents that still need to be addressed.

In this presentation, we introduce a general overview of lipid nanoparticle or liposome production in micromixers, the principles of mixing using curvilinear paths, the key variables controlling lipid-based nanoparticle physicochemical characteristics and approaches that help to substitute toxic solvent residues.

Keywords: Nanoparticle; Liposome; Microfluidic Devices; Micromixers 


\section{What are Lipid Nanoparticles?}

Nanoparticles made of lipids such as liposomes.

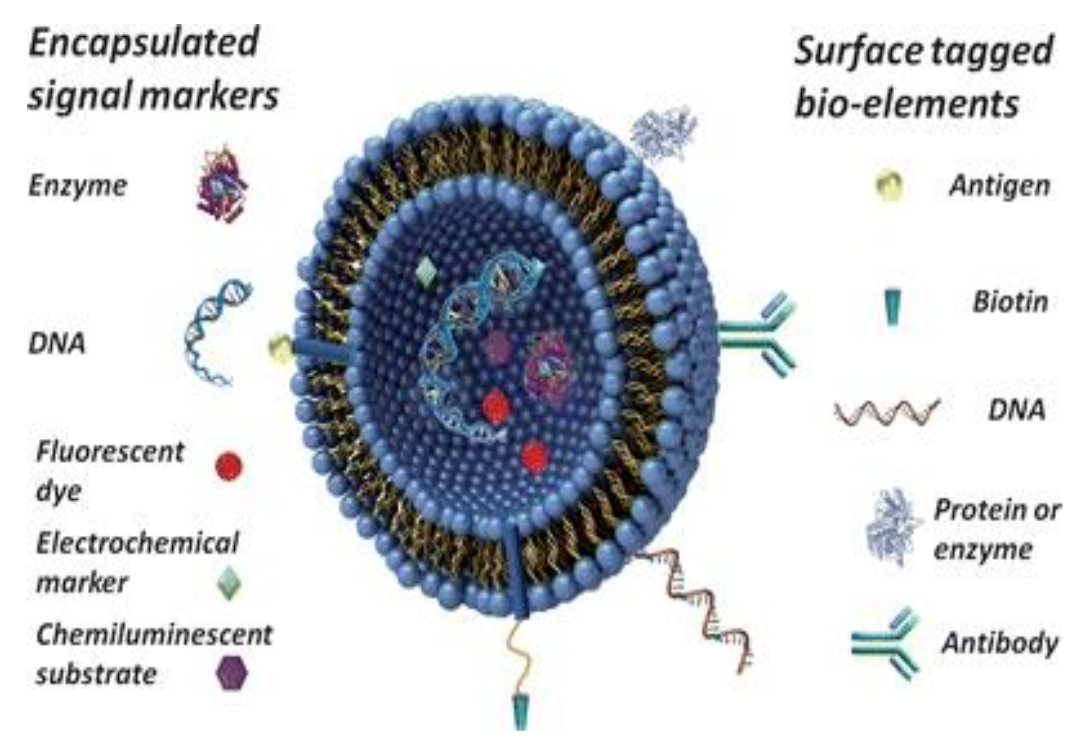

Liu, Q.; Boyd, B. J. Analyst 2013, 138, (2), 391-409)
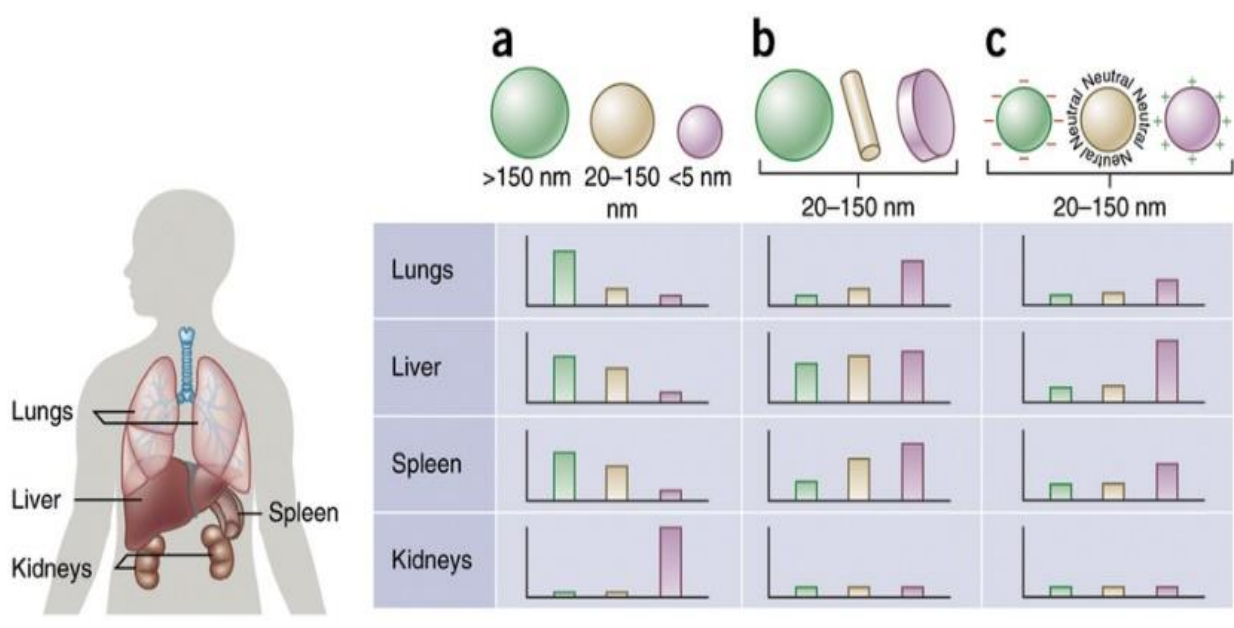

Blanco, E.; Shen, H.; Ferrari, M. Nat. Biotechnol. 2015, 33, (9), 941-51) 


\section{Liposome Applications}

\section{Gene Delivery}

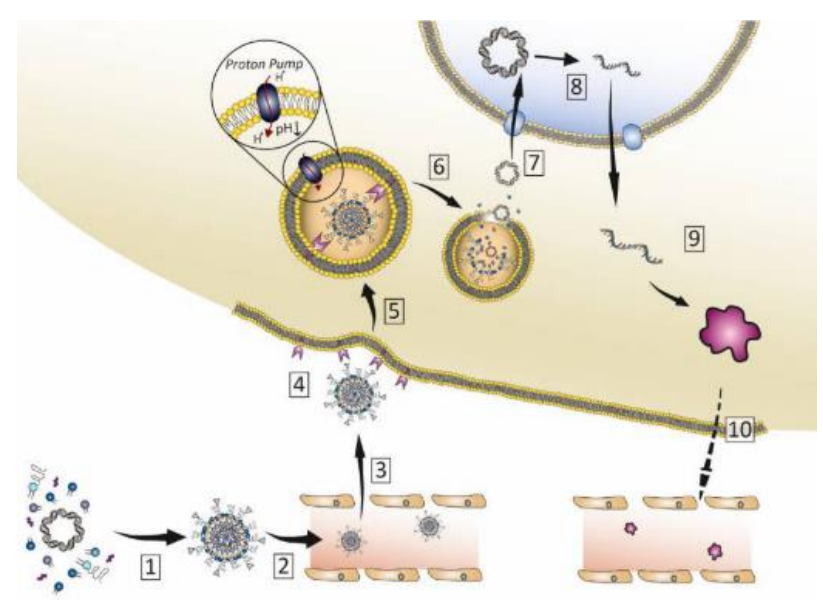

Buck, J.et al. D. ACS Nano 2019, 13, (4), 3754-3782.

siRNA (Patisiran)

mRNA(BNT162b2, mRNA-1273)

\section{Drug Delivery}

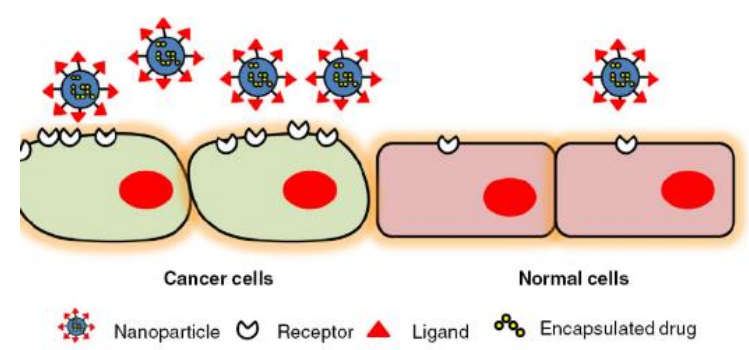

Çağdaş, M et al., Liposomes as Potential Drug Carrier Systems for Drug Delivery. 2014.

Doxorubicin, Amphotericin among others
Imaging and theragnostics

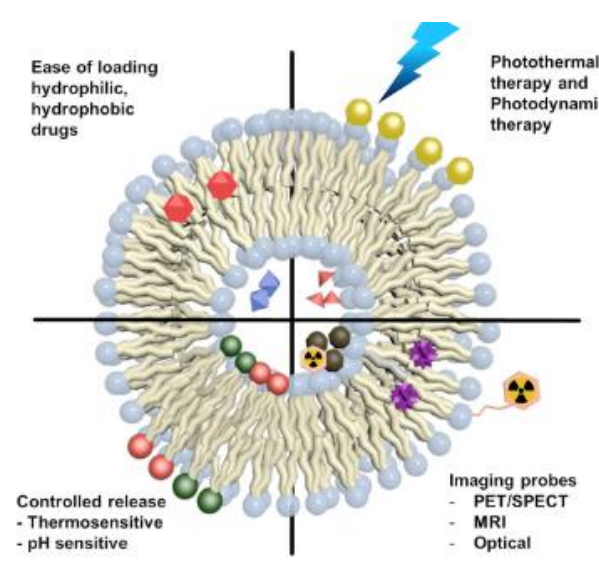

Lee, W.; Im, H.-J. Nuclear Medicine and Molecular Imaging 2019, 53, (4), 242-246.

\author{
Radioisotopes, \\ gold NP, \\ fluorescence dye
}


Nanomedicines Market

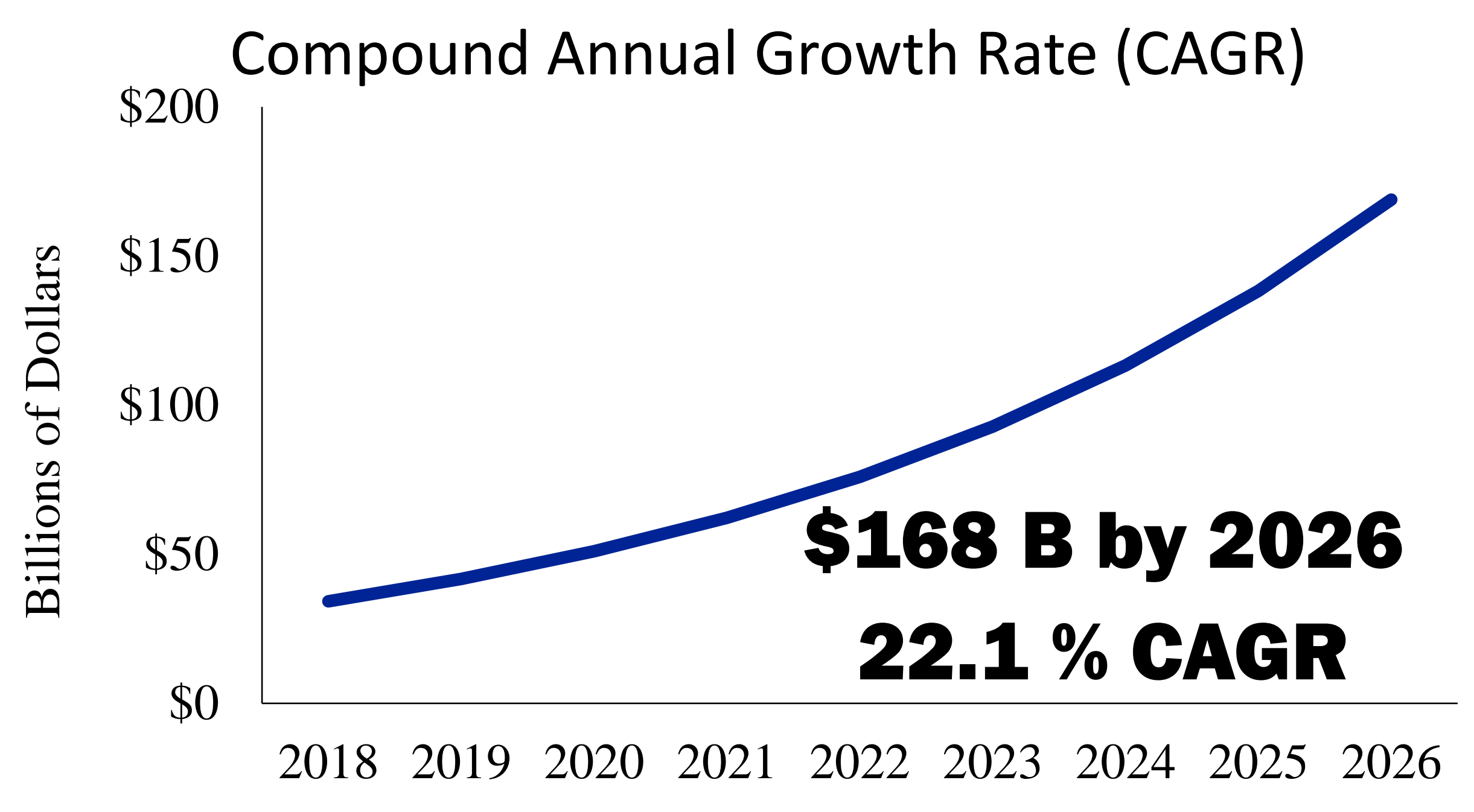

(Business-Wire, 2019) 


\section{Nanoprecipitation}

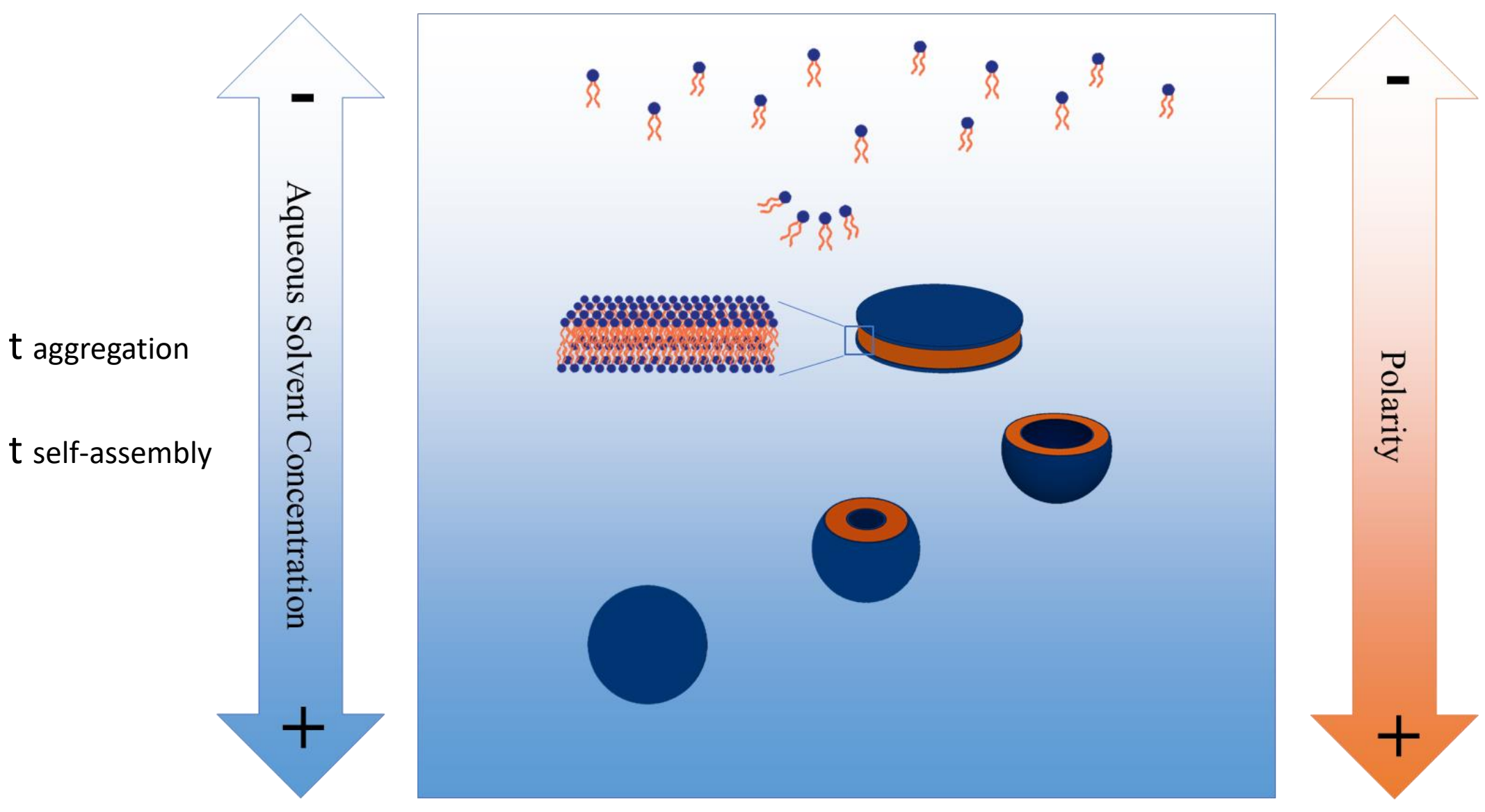




\section{How can we improve mixing? Micromixers}

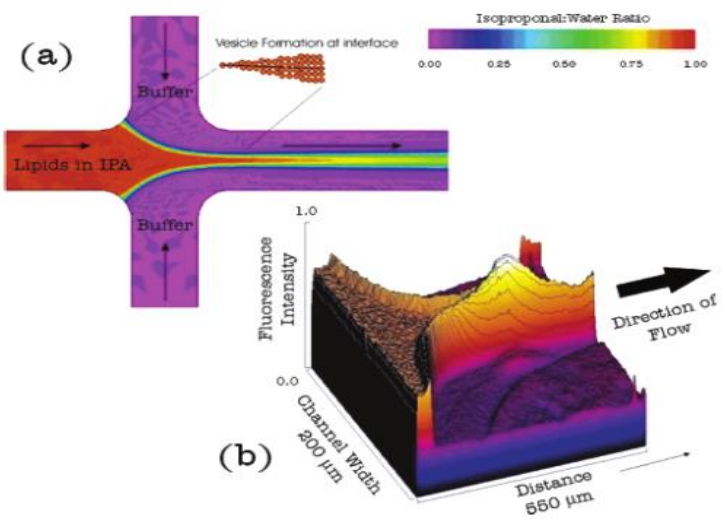

Jahn, A.; Vreeland, W. N.; Gaitan, M.; Locascio, L. E. J. Am. Chem. Soc. 2004, 126, (9), 2674-2675.

\section{MHF}

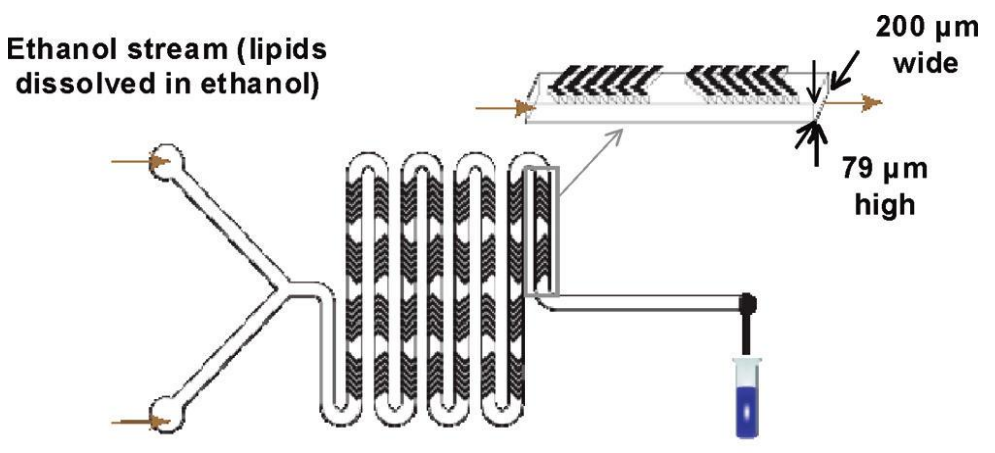

Aqueous stream

Zhigaltsev, I. V.; Belliveau, N.; Hafez, I.; Leung, A. K. K.; Huft, J.; Hansen, C.; Cullis, P.

R. Langmuir 2012, 28, (7), 3633-3640.

SHM

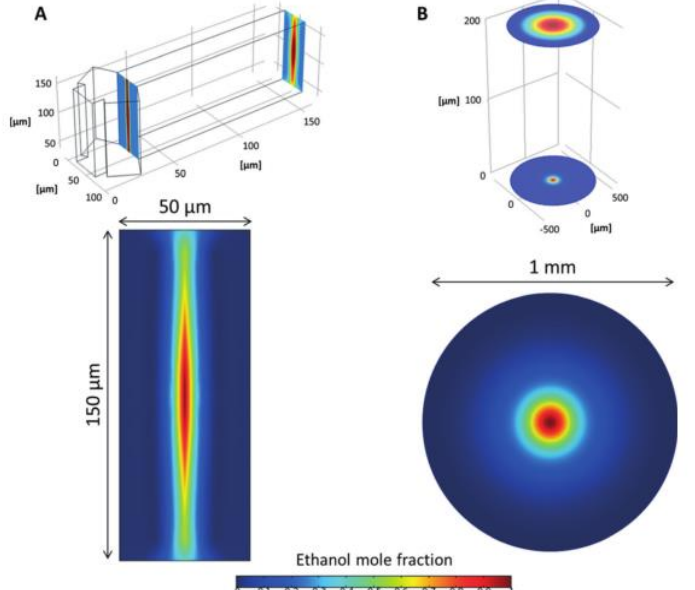

Hood, R. R.; DeVoe, D. L.; Atencia, J.; Vreeland, W. N.; Omiatek, D. M. Lab on a Chip 2014, 14, (14), 2403-2409.

3D-MHF

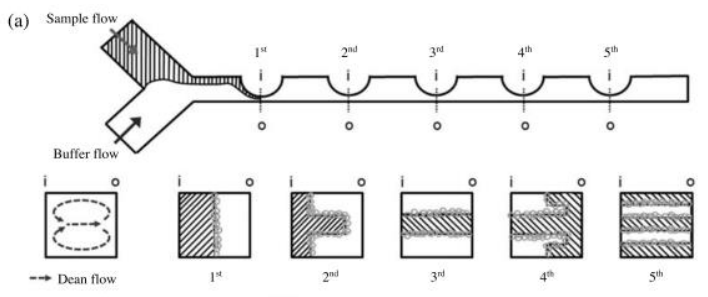

Lee, J.; Lee, M. G.; Jung, C.; Park, Y.-H.; Song, C.; Choi, M. C.; Park, H. G.; Park, J.-K. BioChip Journal 2013, 7, (3), 210-217.

\section{DEAN FLOW BASED MICROMIXER}

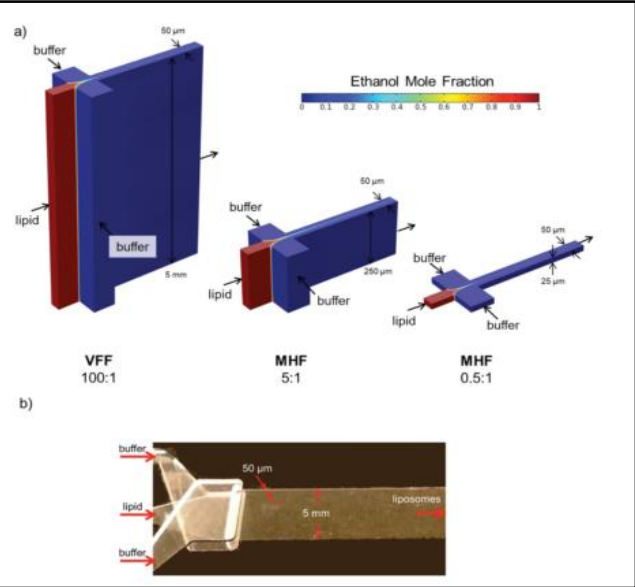

Hood, R. R.; DeVoe, D. L. Small 2015, $11,(43), 5790-9$.

VFF

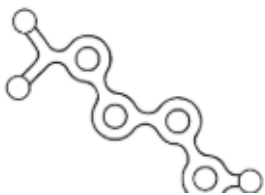

Precision Nanosystems Webb et al. 2020

TrM 


\section{Contributions}

- New microfluidic devices tailored to produce controlled-size liposomes.

- Production of liposomes in a size range of commercially available liposomal formulations

- Model to predict liposome size using microfluidic devices.

- Molecular factors influence over liposome physiochemical characteristics.

- Role of the organic solvent in liposome properties.

- Substitution of conventional organic solvents for Transcutol for liposome production.

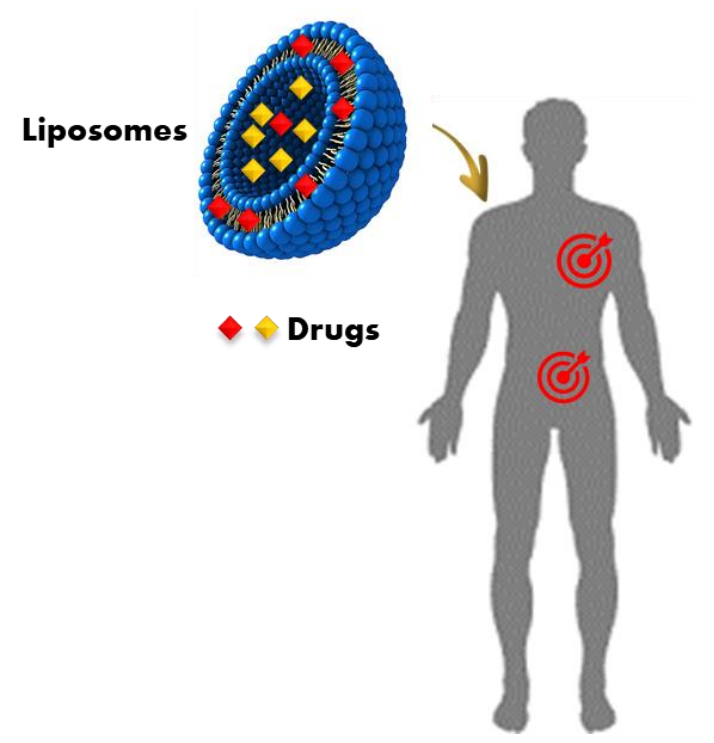

Control of liposome properties

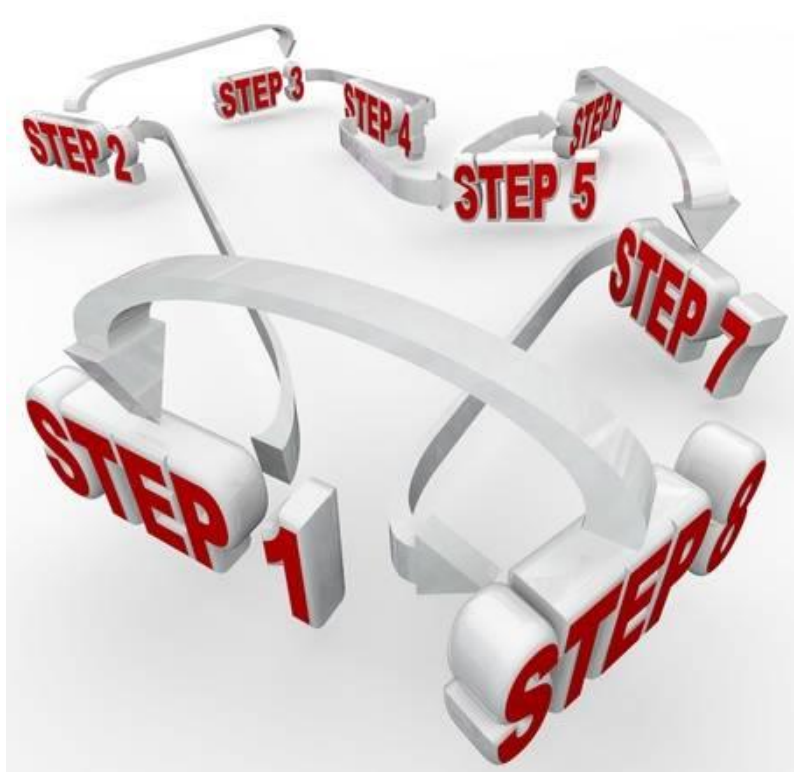

Reproducibility and reduction of steps (organic solvent removal)

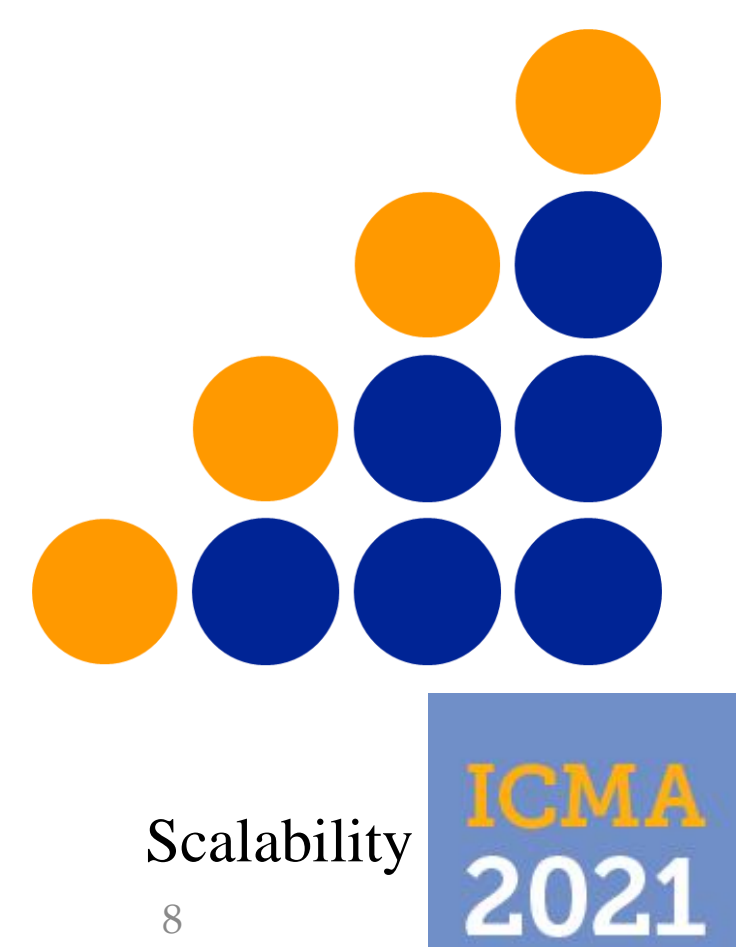




\section{General Methodology}

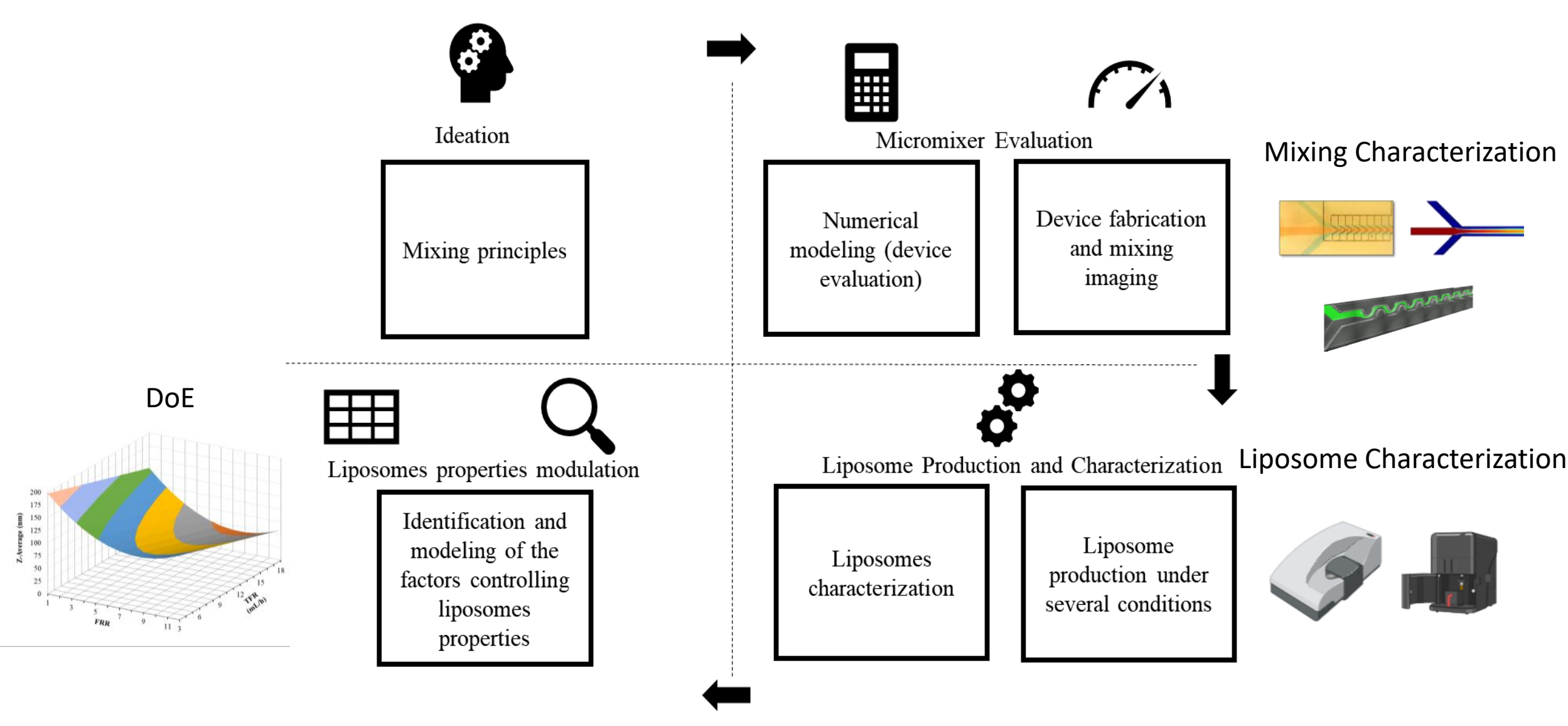




\section{PDM-Micromixer (Periodic Disturbance Mixer)}
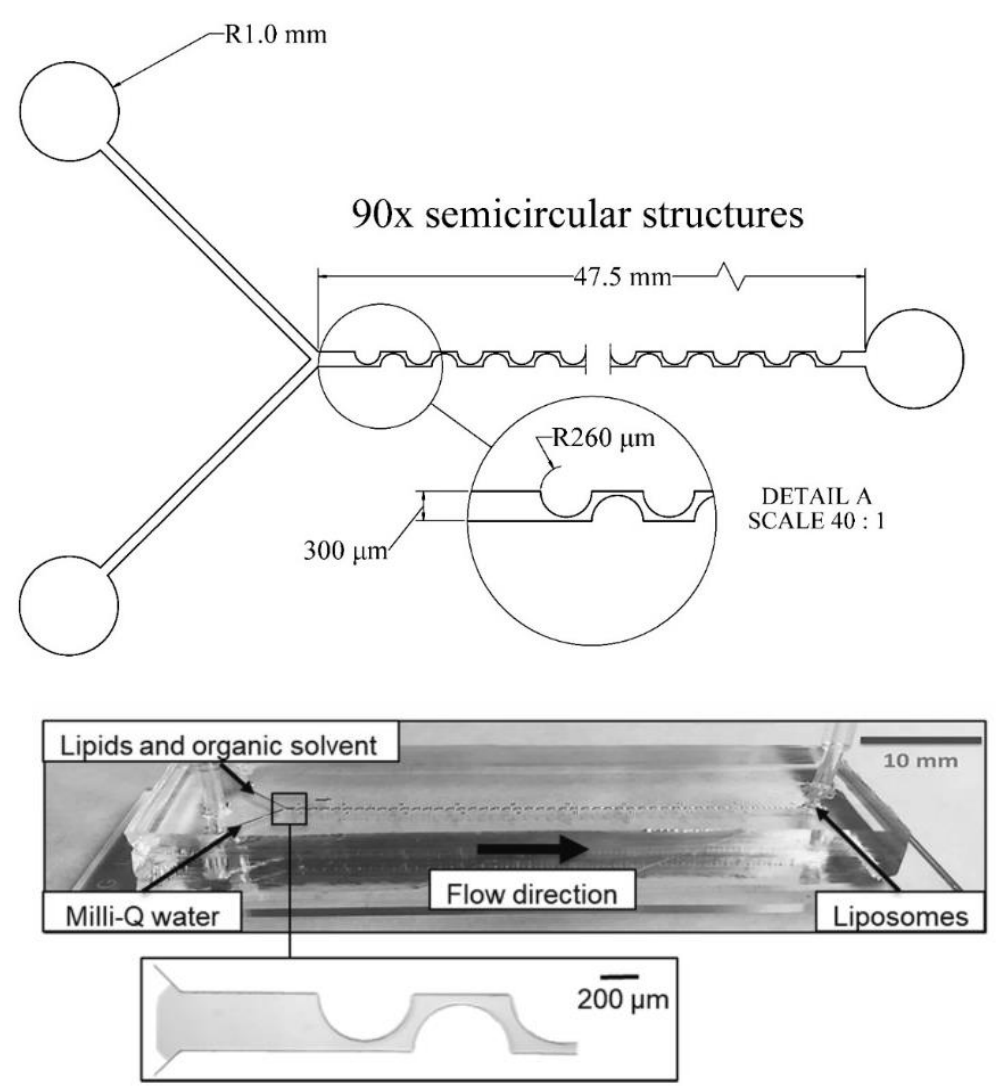

López, R. R.; et al. The Effect of Different Organic Solvents in Liposome Properties Produced in a Periodic Disturbance Mixer: Transcutol ${ }^{\circledR}$, a potential organic solvent replacement. In Colloids Surf. B. Biointerfaces, 2020.

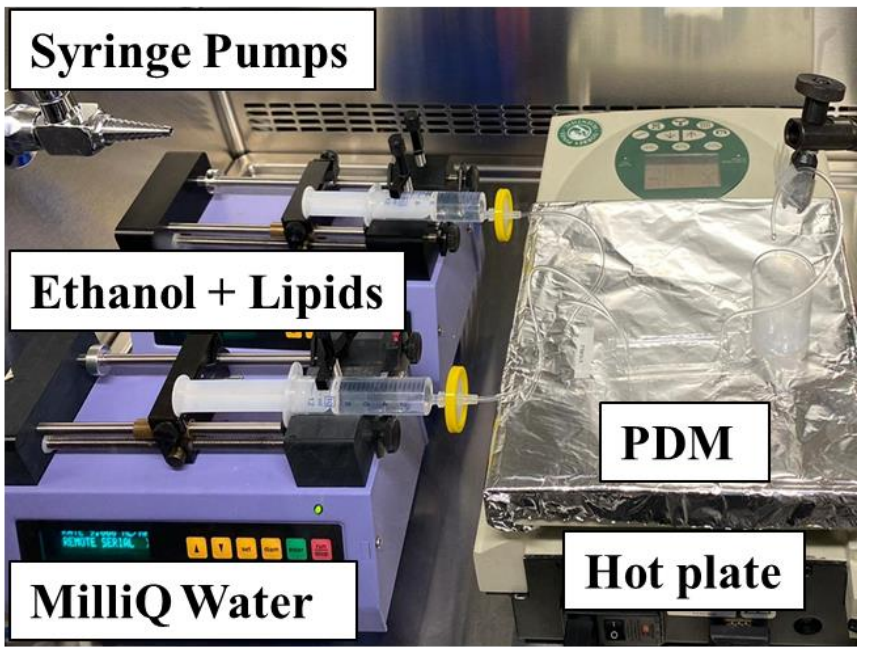

López, R. R.; et al. Lipid Fatty Acid Chain Influence over Liposome Physicochemical Characteristics Produced in a Periodically Disturbed Micromixer. In IEEE Nano 2020, IEEE: Montreal, 2020.

(A)

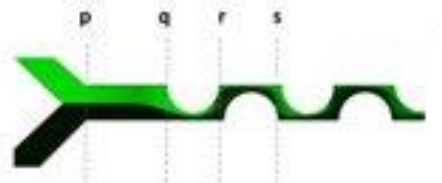

(8)
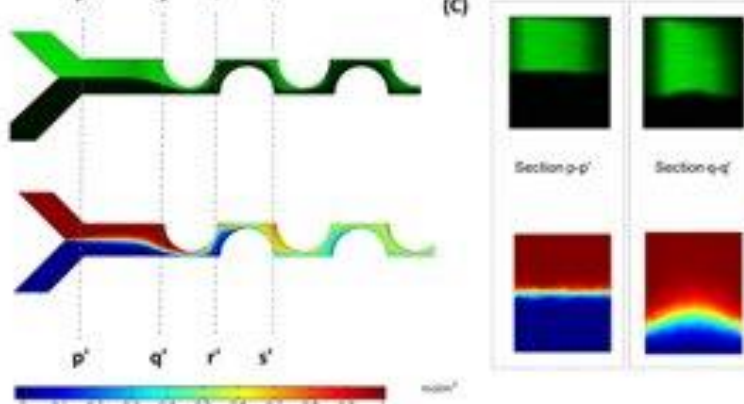

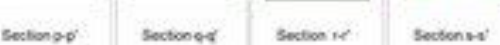
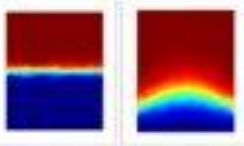

López, R. R.; et al.., Parametric Study of the Factors

Influencing Liposome Physicochemical Characteristics in a Periodic Disturbance Mixer. In Langmuir, XX ed.; 2020; Vol. $X X, p X X$. 


\section{Modeling Liposome Properties}

\section{Factors}

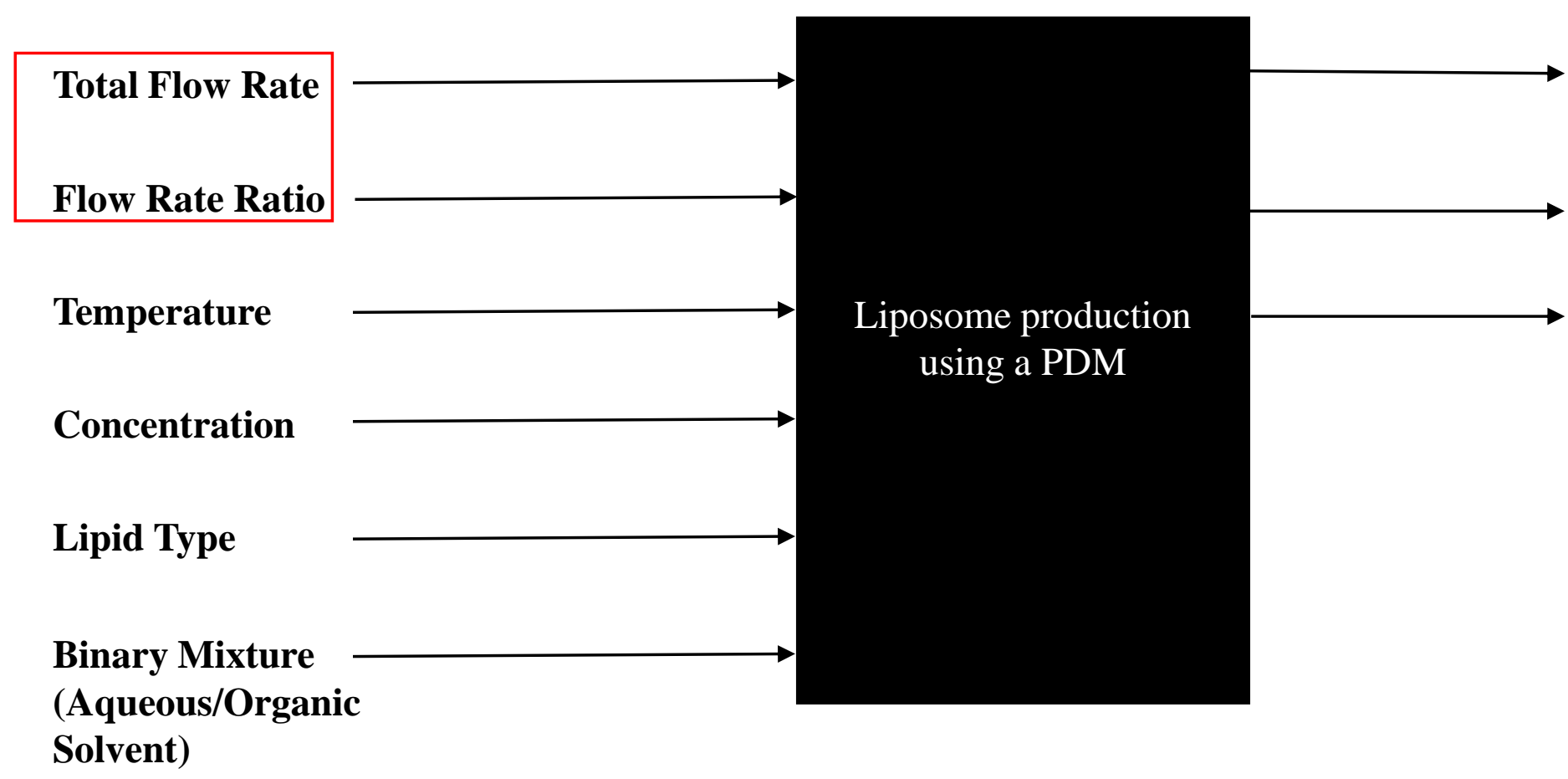

López Salazar, R. R. Controlled liposome production using micromixers based on Dean flow dynamics. École de technologie supérieure, 2020.

\section{Responses}

Z-Average (Diameter)

PDI (Homogeneity)

Zeta Potential (Surface Properties) 


\section{DoE and Surface Response Methodology}
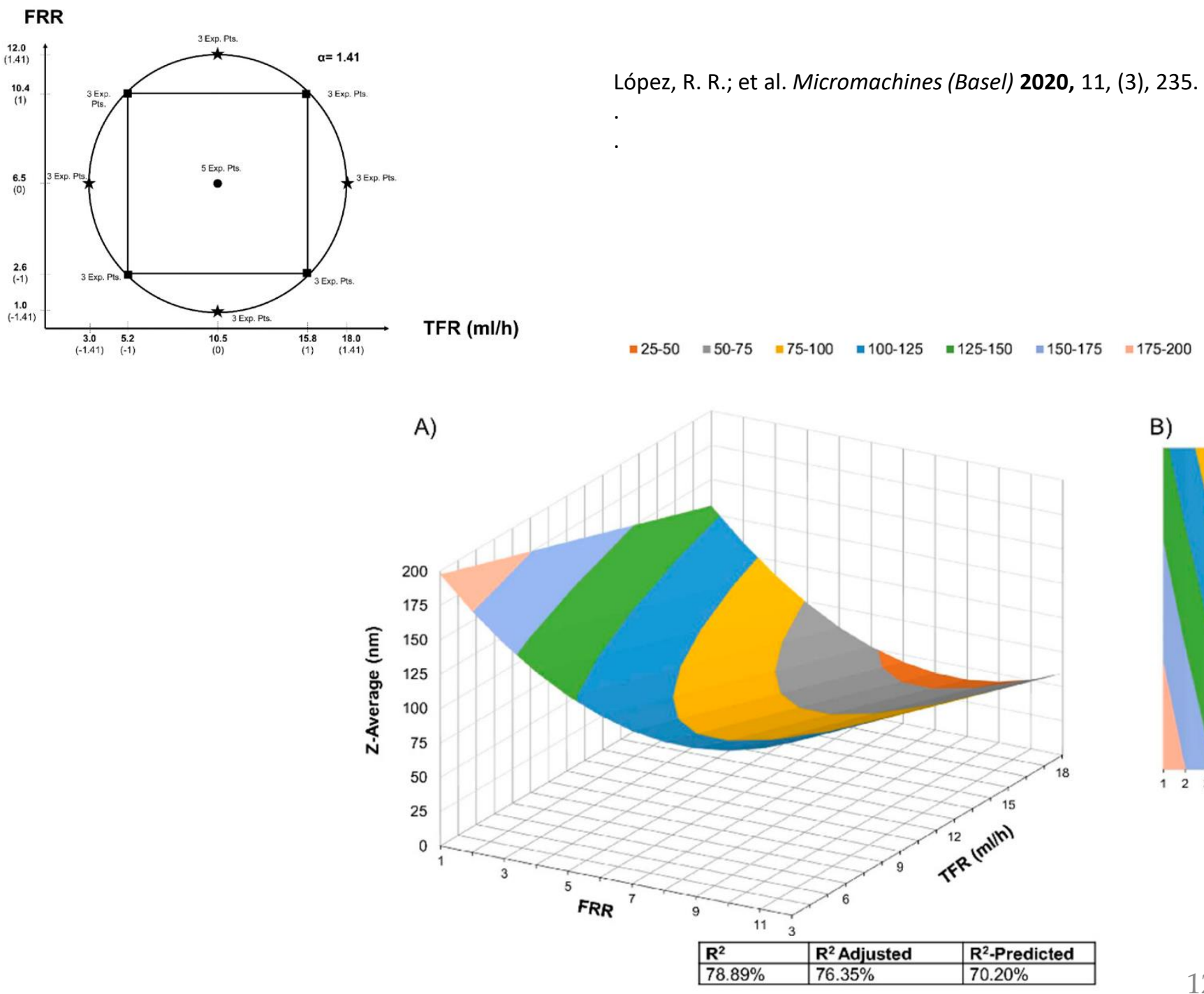

B)

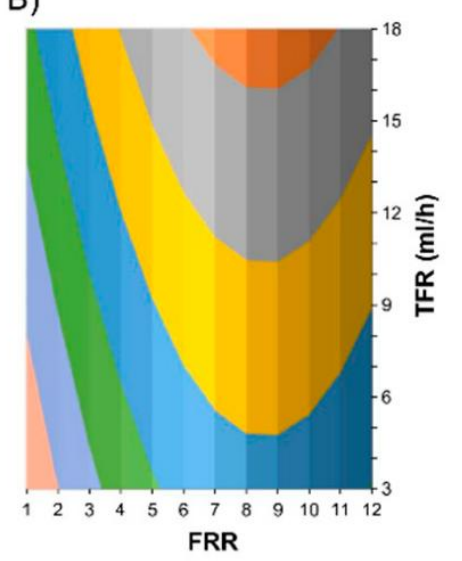




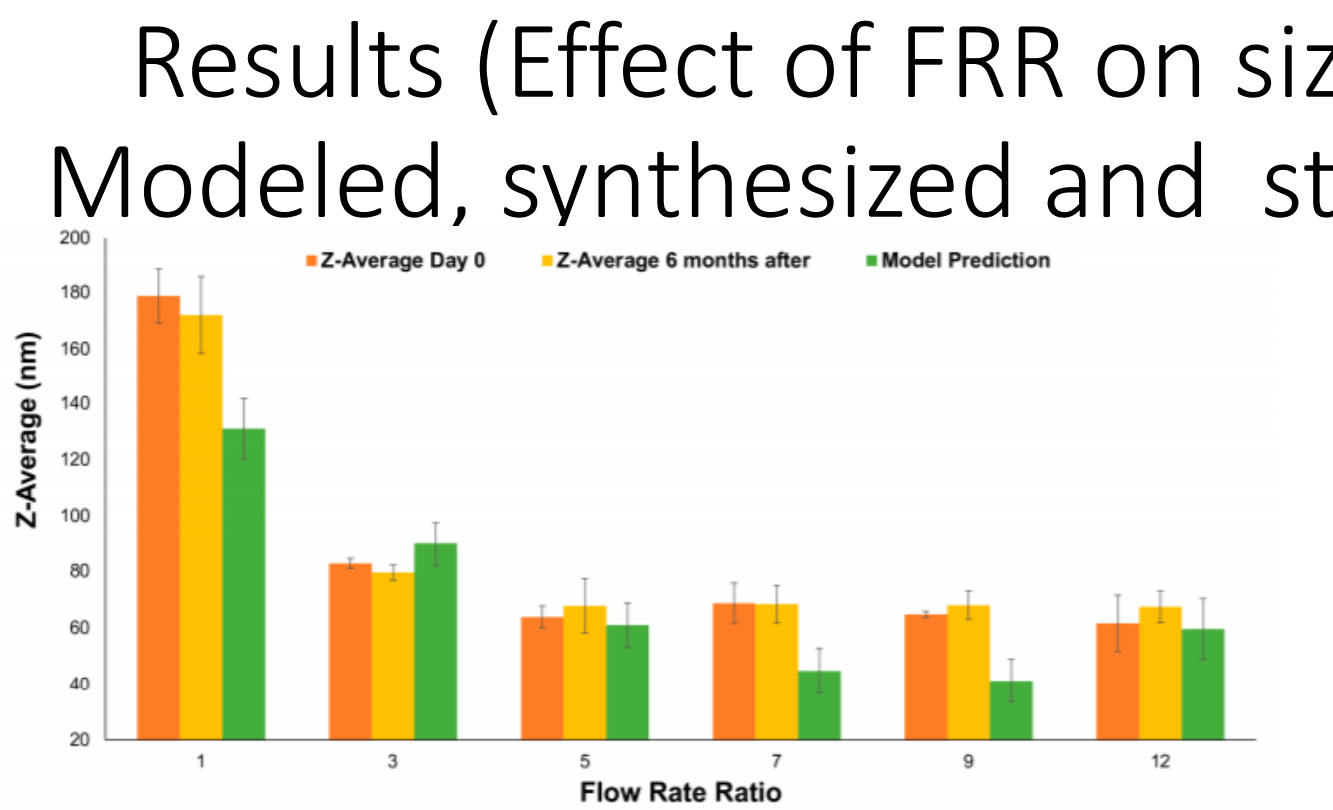

Z-average (nm) vs. FRR at a constant TFR $=18 \mathrm{~mL} / \mathrm{h}$. In orange, the Z-average immediately after production, in yellow six months after, and in green the model prediction. $n=3$. Error bars indicate $+/-1$ standard deviation (SD) for samples and SE fit for the model prediction.

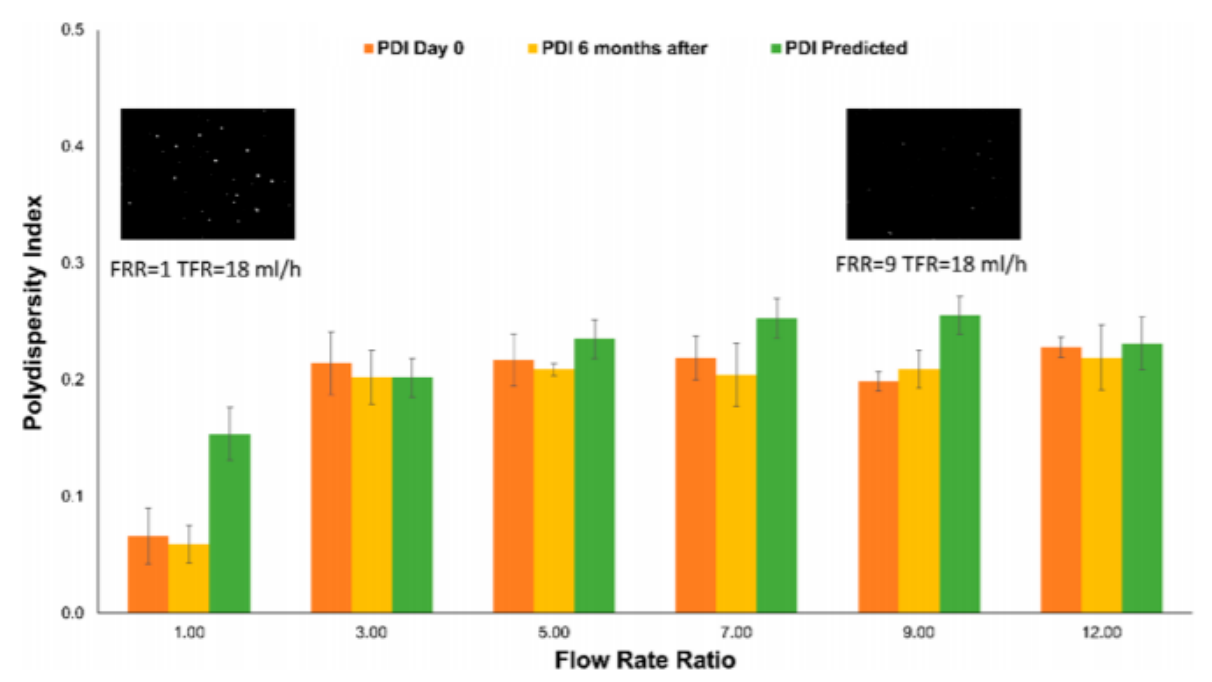

Liposomes PDI measurements immediately after production (orange), six months after(yellow), and the model prediction (green) at a constant TFR $=18 \mathrm{~mL} / \mathrm{h} . n=3$, error bars indicate $+/-1 \mathrm{SD}$ for samples and SE fit for the model prediction. Images are taken from videos using NTA

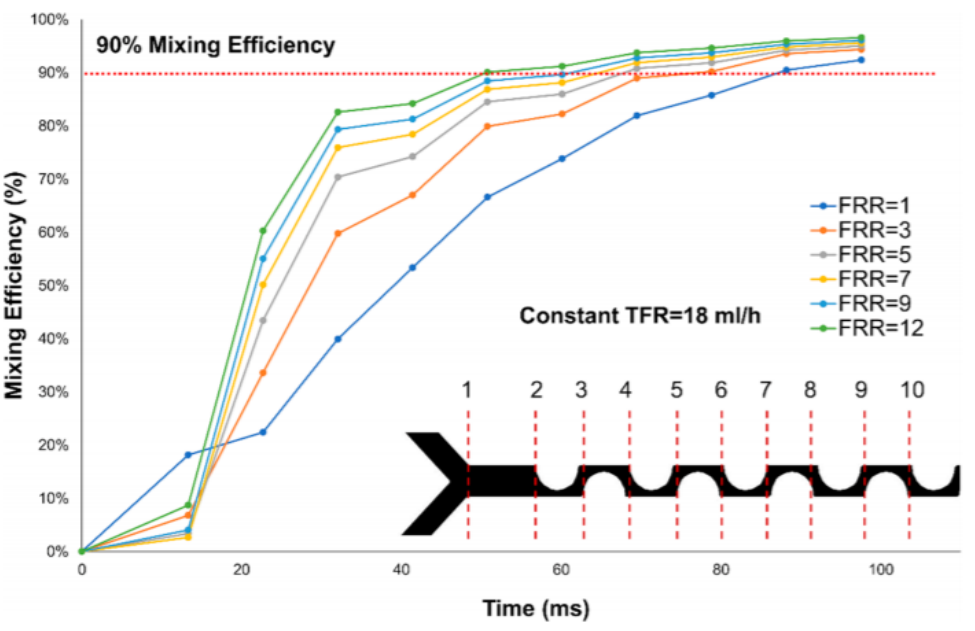

Mixing efficiency at different FRRs. Each data point corresponds to a cross-section for a total of 10 data points from $1-10$ 


\section{Results (Effect of FRR/TFR on size, PDI \& Zeta potential)}

(A) Constant FRR $=8.56 \mathrm{~T}=70^{\circ} \mathrm{C} \mathrm{c}=5 \mathrm{mM} \quad$ (B)

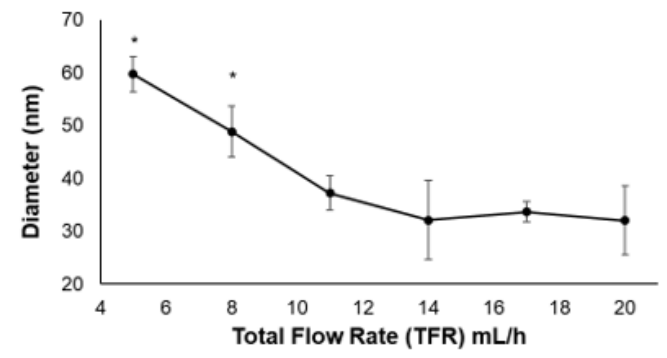

(C)

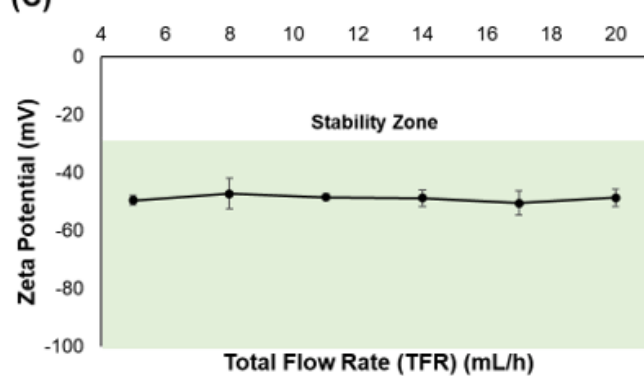

(A) Constant TFR $=18 \mathrm{~mL} / \mathrm{h} \mathrm{T}=70^{\circ} \mathrm{C} \mathrm{c}=5 \mathrm{mM}$ (B)

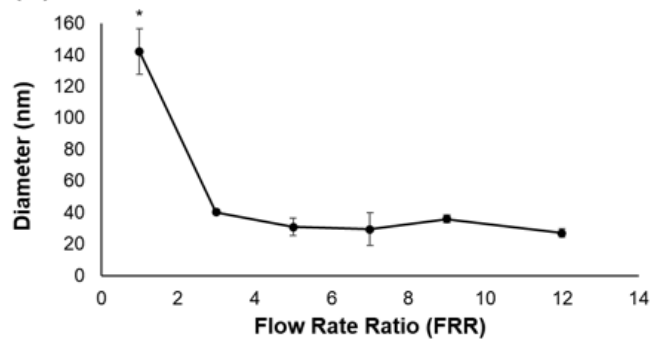

(C)

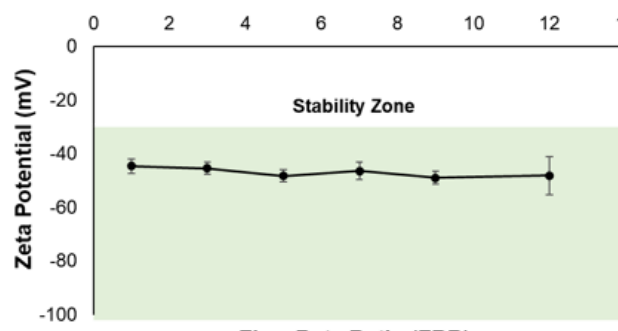

Flow Rate Ratio (FRR)
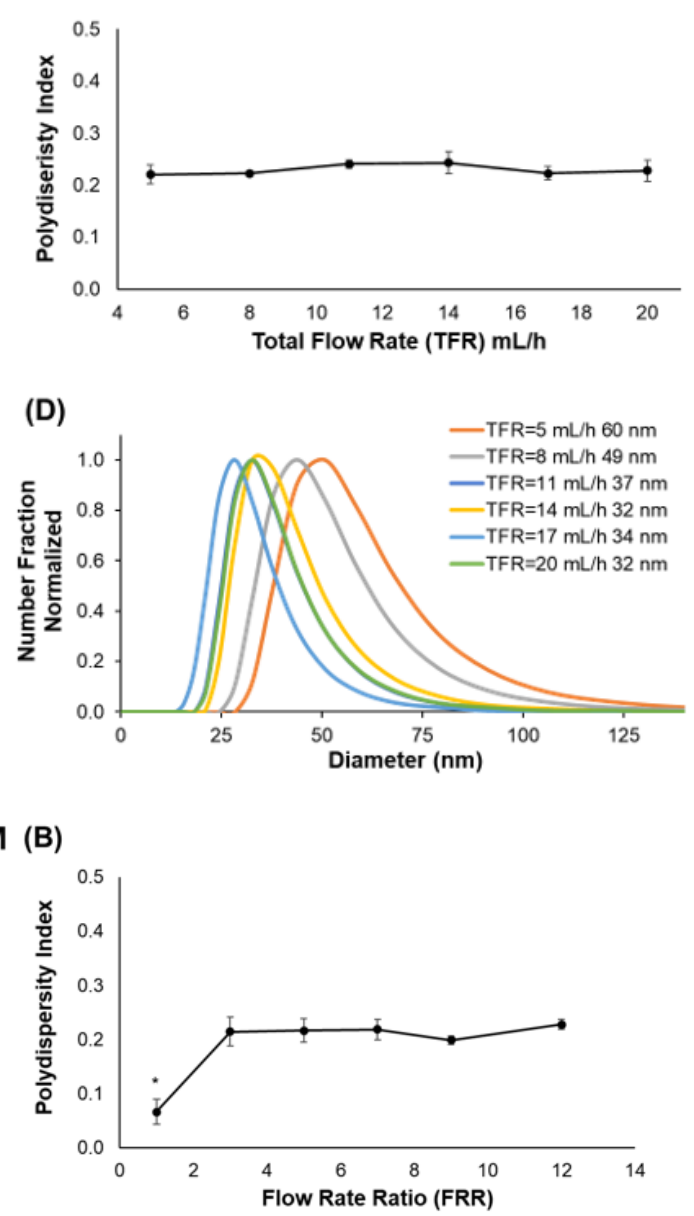

(D)

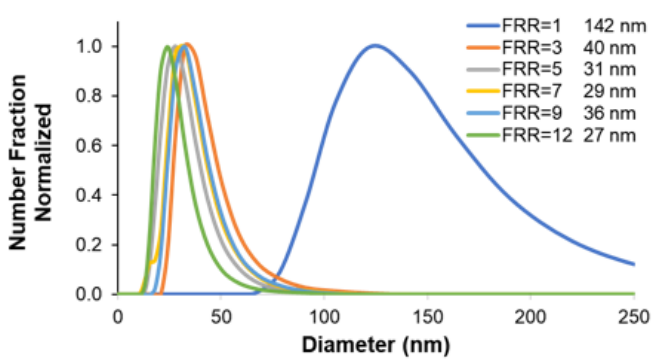

TFR

from 3 to $10 \mathrm{ml} / \mathrm{h}$

López, R. R.; et al.., Parametric Study of the Factors

Influencing Liposome Physicochemical Characteristics in a Periodic Disturbance Mixer. In Langmuir, XX ed.; 2020; Vol. $X X, p X X$

\section{FRR}

from 1 to 12 


\section{Results (Effect of lipids on size, PDI \& Zeta potential)}

(A)

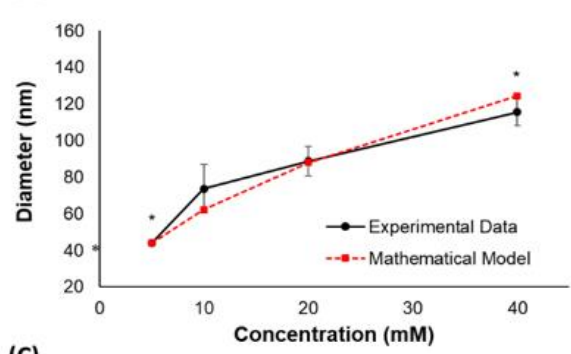

(C)

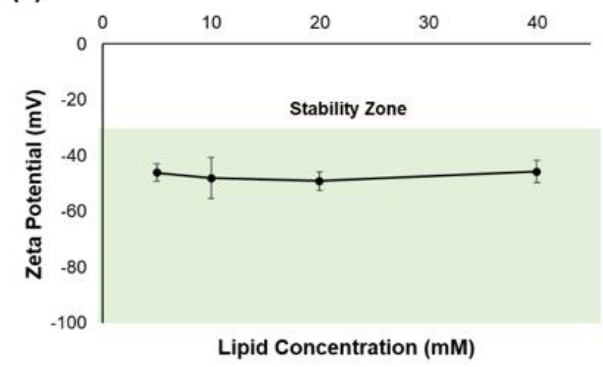

Constant FRR $=8.56, \mathrm{TFR}=18 \mathrm{~mL} / \mathrm{h} \mathrm{T}=40^{\circ} \mathrm{C}$ Main lipid DSPC

(A)
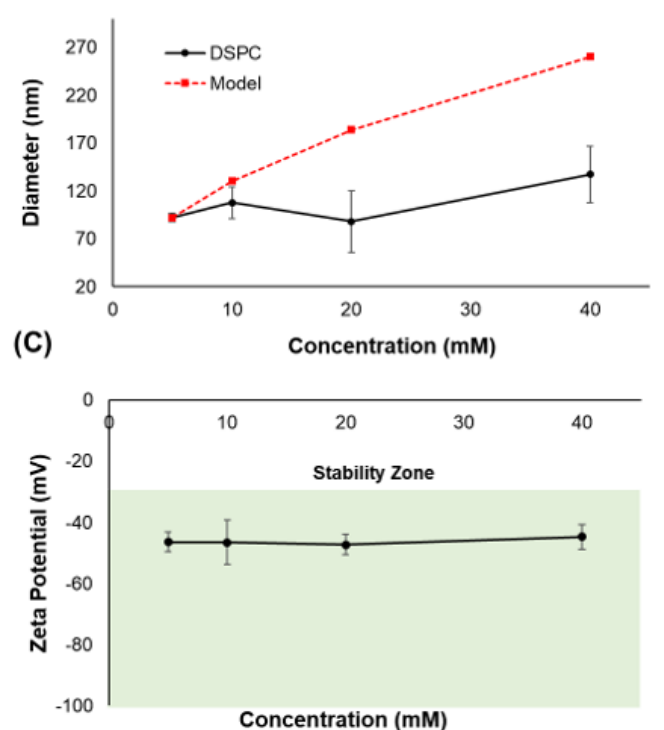

(B)

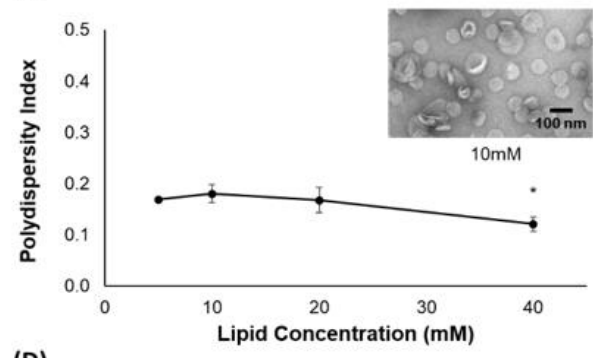

(D)

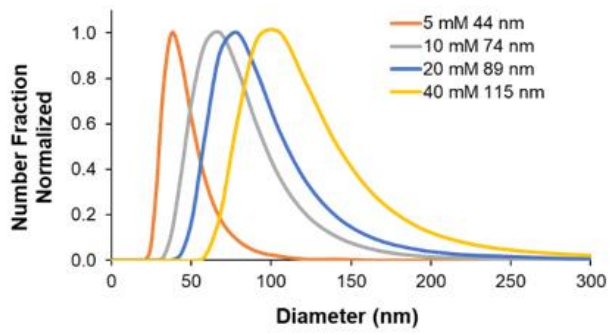

(B)

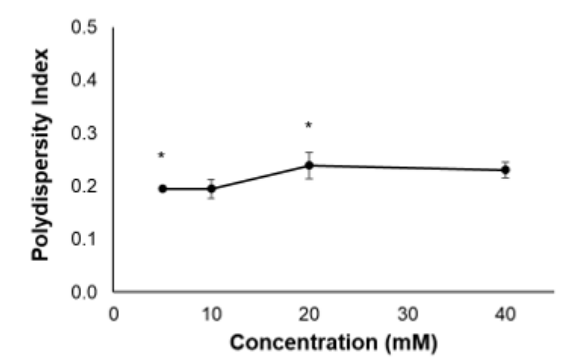

(D)

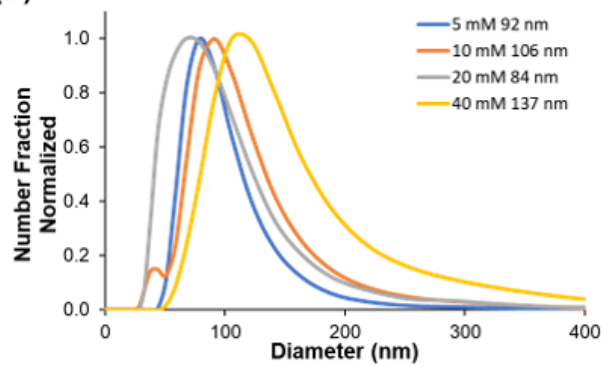

\section{Lipid}

DMPC

López, R. R.; et al.., Parametric Study of the Factors Influencing Liposome Physicochemical Characteristics in a Periodic Disturbance Mixer. In Langmuir, XX ed.; 2020; Vol. $\mathrm{XX}, \mathrm{p} \mathrm{XX}$

\section{Lipid DSPC}




\section{Results (Effect of different solvents)}

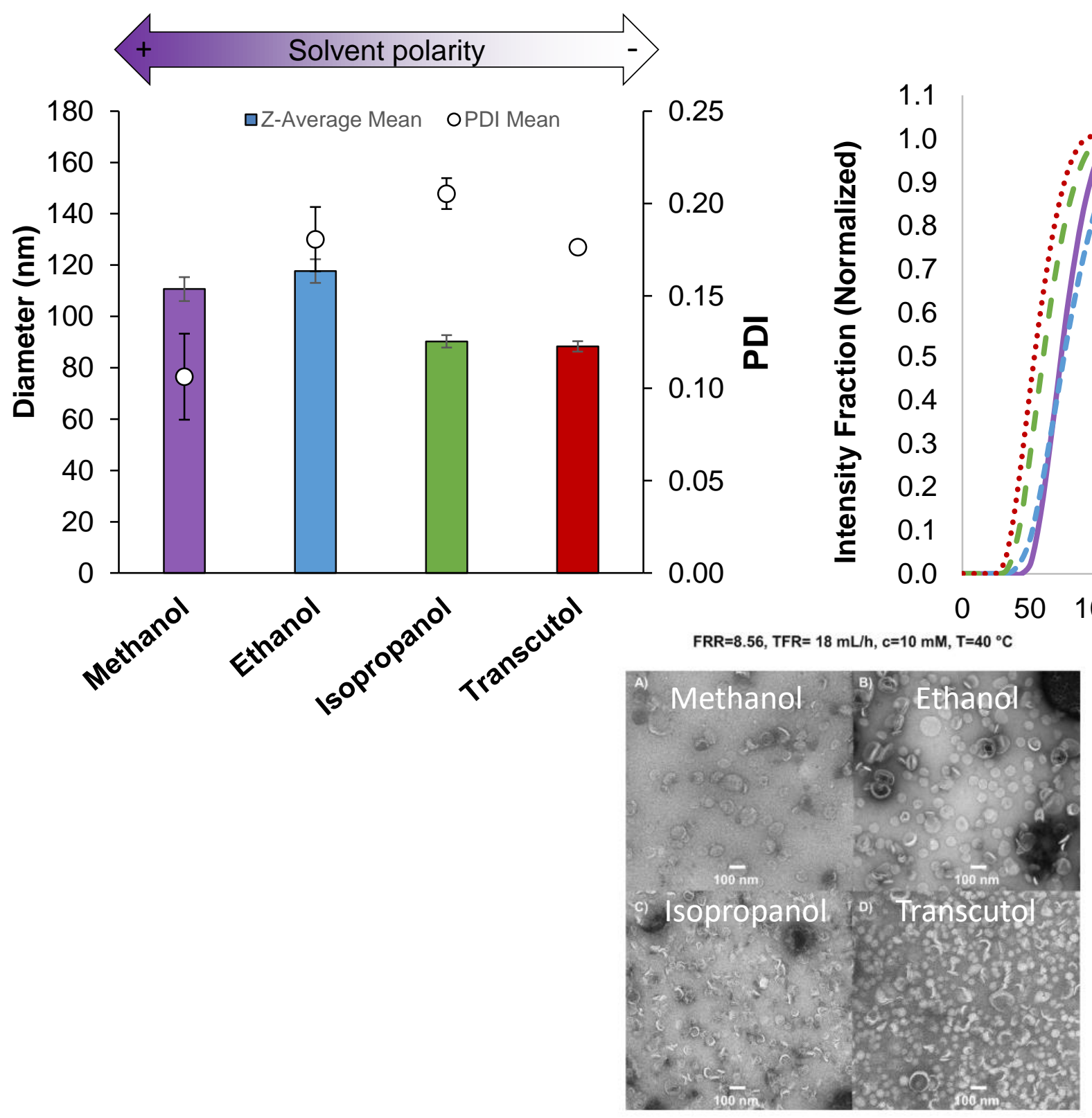

López, R. R.; et al. The Effect of Different Organic Solvents in Liposome Properties Produced in a Periodic Disturbance Mixer: Transcutol ${ }^{\circledR}$, a potential organic solvent replacement. In Colloids Surf. B. Biointerfaces, 2020. 


\section{Results (Effect of different lipid concentrations and $\mathrm{T}^{\circ}$ )}

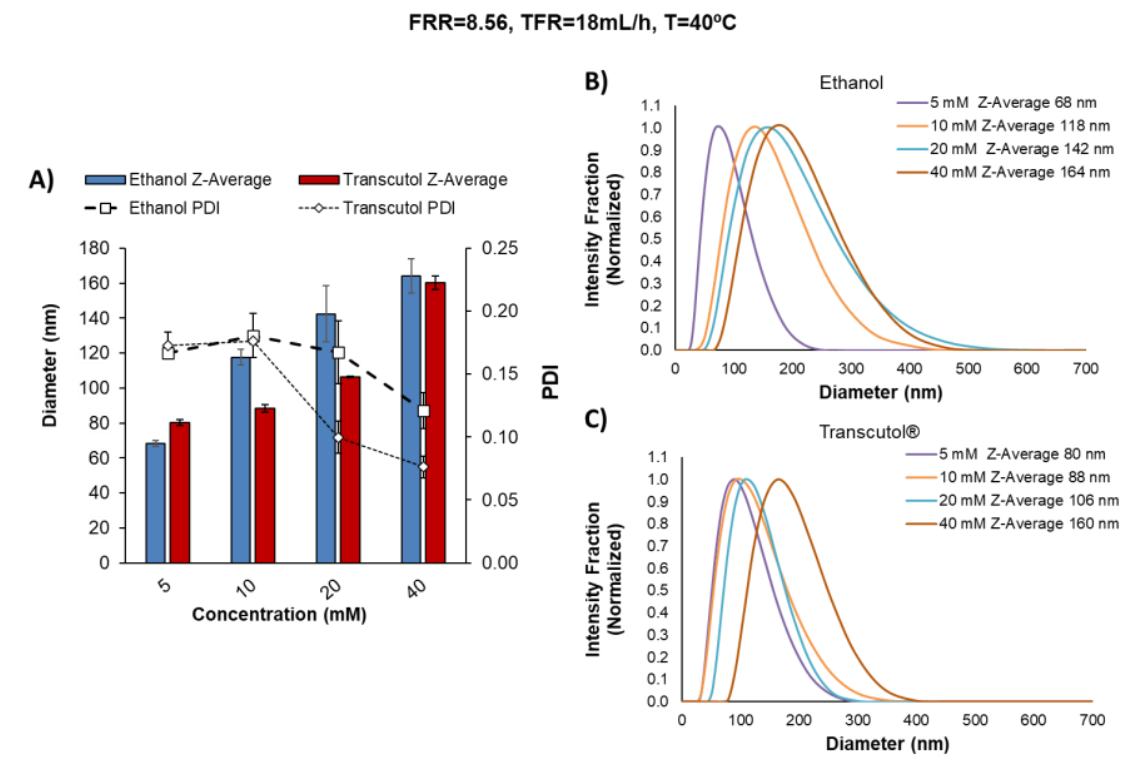

\section{Lipid concentration \\ from $5 \mathrm{mM}$ to $40 \mathrm{mM}$}

López, R. R.; et al. The Effect of Different Organic Solvents in Liposome Properties Produced in a Periodic Disturbance Mixer: Transcutol ${ }^{\circledR}$, a potential organic solvent replacement. In Colloids Surf. B. Biointerfaces, 2020.

A)

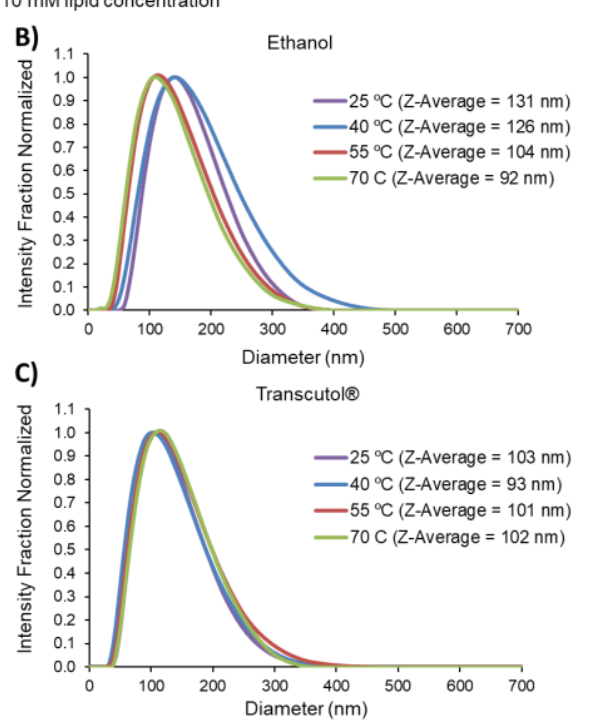

\section{Temperature \\ from $250 \mathrm{C}$ to $700 \mathrm{C}$}

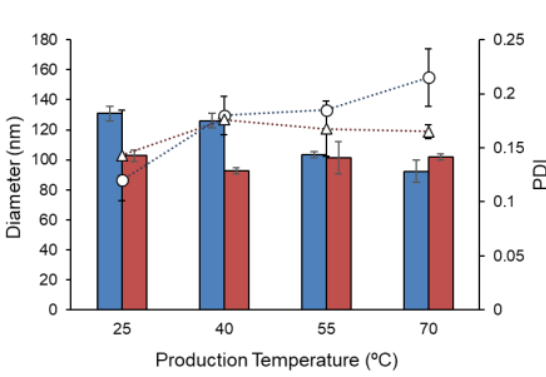




\section{Challenges and future work}

- Continuous solvent removal

- Production yield (PNI). Toroidal micromixer (TrM)

- Production parallelization

- Synthesis and size characterization integration

Cell to cell communication and cancer research EVs liposomes

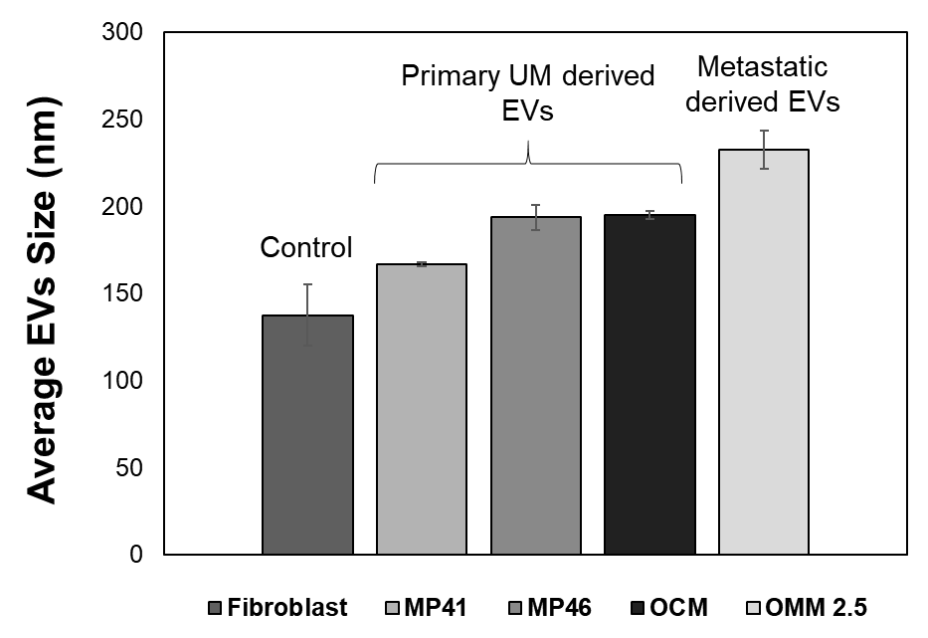

(López et al. 2020) ARVO 2020
Parallelization

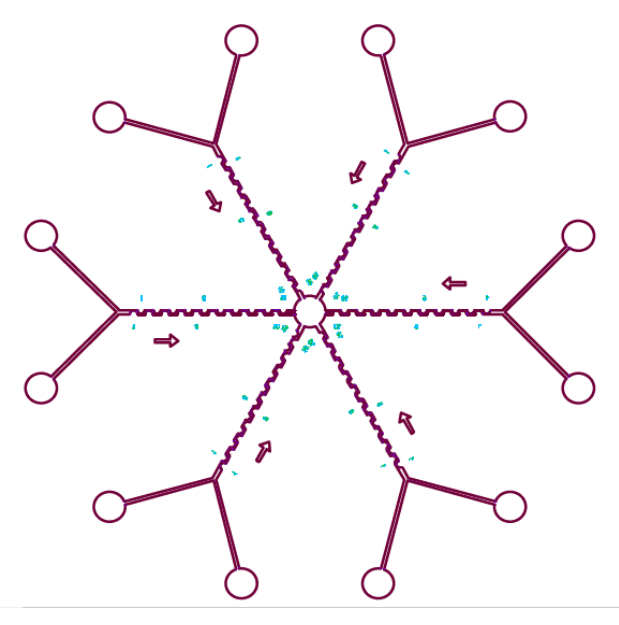

Unpublished 


\section{Supplementary Materials and References}

1. Liu, Q.; Boyd, B. J. Analyst 2013, 138, (2), 391-409.

2. Blanco, E.; Shen, H.; Ferrari, M. Nat. Biotechnol. 2015, 33, (9), 941-51.

3. Buck, J.; Grossen, P.; Cullis, P. R.; Huwyler, J.; Witzigmann, D. ACS Nano 2019, 13, (4), 3754-3782.

4. Çağdaş, M.; Sezer, A. D.; Bucak, S., Liposomes as Potential Drug Carrier Systems for Drug Delivery. 2014.

5. Lee, W.; Im, H.-J. Nuclear Medicine and Molecular Imaging 2019, 53, (4), 242-246.

6. Business-Wire Global Nanopharmaceuticals Market to Surpass US\$168.91 Billion by 2026. https://www.bloomberg.com/pressreleases/2019-02-15/global-nanopharmaceuticals-market-to-surpass-us-168-91-billion-by-2026 (January. 20 2020),

7. López, R. R.; G. Font de Rubinat, P.; Sánchez, L.-M.; Alazzam, A.; Bergeron, K.-F.; Mounier, C.; Stiharu, I.; Nerguizian, V., The Effect of Different Organic Solvents in Liposome Properties Produced in a Periodic Disturbance Mixer: Transcutol ${ }^{\circledR}$, a potential organic solvent replacement. In Colloids Surf. B. Biointerfaces, 2020.

8. Jahn, A.; Vreeland, W. N.; Gaitan, M.; Locascio, L. E. J. Am. Chem. Soc. 2004, 126, (9), 2674-2675.

9. Hood, R. R.; DeVoe, D. L.; Atencia, J.; Vreeland, W. N.; Omiatek, D. M. Lab on a Chip 2014, 14, (14), 2403-2409.

10. Hood, R. R.; DeVoe, D. L. Small 2015, 11, (43), 5790-9.

11. Zhigaltsev, I. V.; Belliveau, N.; Hafez, I.; Leung, A. K. K.; Huft, J.; Hansen, C.; Cullis, P. R. Langmuir 2012, 28, (7), 3633-3640.

12. Lee, J.; Lee, M. G.; Jung, C.; Park, Y.-H.; Song, C.; Choi, M. C.; Park, H. G.; Park, J.-K. BioChip Journal 2013, 7, (3), $210-217$.

13. Webb, C.; Forbes, N.; Roces, C. B.; Anderluzzi, G.; Lou, G.; Abraham, S.; Ingalls, L.; Marshall, K.; Leaver, T. J.; Watts, J. A.; Aylott, J. W.; Perrie, Y. Int. J. Pharm. 2020, 582, 119266.

14. López, R. R.; Ocampo, I.; G. Font de Rubinat, P.; Sánchez, L.-M.; Alazzam, A.; Tsering, T.; Bergeron, K.-F.; Camacho-León, S.; Burnier, J. V.; Mounier, C.; Stiharu, I.; Nerguizian, V., Parametric Study of the Factors Influencing Liposome Physicochemical Characteristics in a Periodic Disturbance Mixer. In Langmuir, XX ed.; 2020; Vol. XX, p XX.

15. López, R. R.; Ocampo, I.; Sánchez, L.-M.; Alazzam, A.; Bergeron, K.-F.; Camacho-León, S.; Mounier, C.; Stiharu, I.; Nerguizian, V. Micromachines (Basel) 2020, 11, (3), 235.

16. López Salazar, R. R. Controlled liposome production using micromixers based on Dean flow dynamics. École de technologie supérieure, 2020.

17. López, R. R.; G. Font de Rubinat, P.; Sánchez, L.-M.; Alazzam, A.; Bergeron, K.-F.; Mounier, C.; Stiharu, I.; Nerguizian, V., The Effect of Different Organic Solvents in Liposome Properties Produced in a Periodic Disturbance Mixer: Transcutol ${ }^{\circledR}$, a potential organic solvent replacement. In Colloids Surf. B. Biointerfaces, 2020. 


\section{Acknowledgments}

Collaboration of the following universities
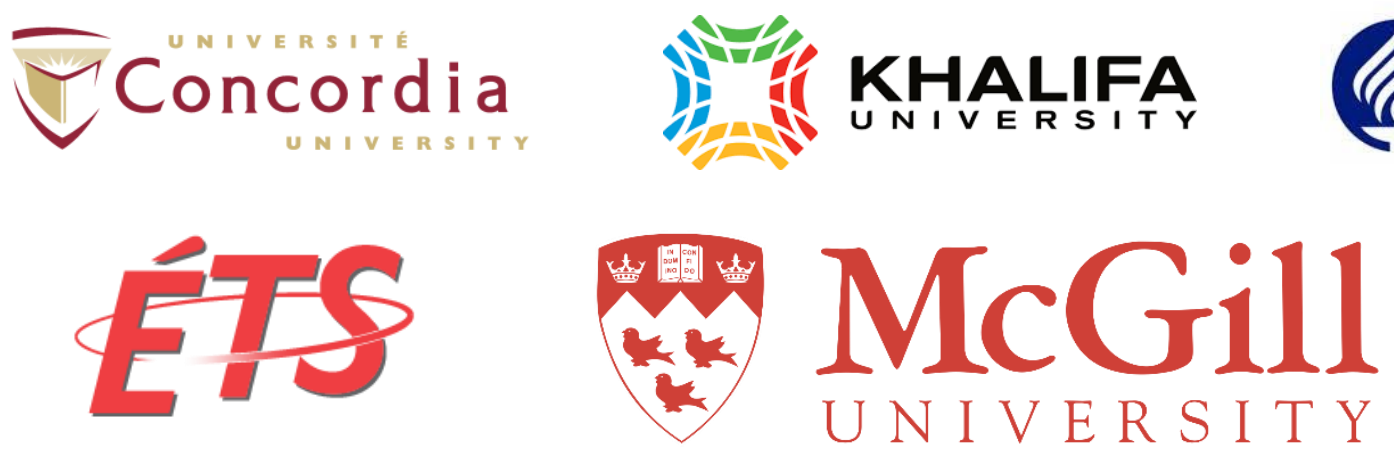

Tecnológico de Monterrey
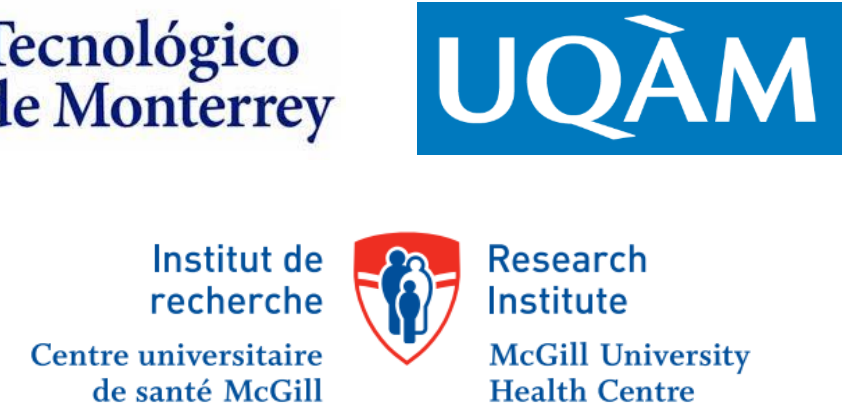

Support from the following institutions/companies:
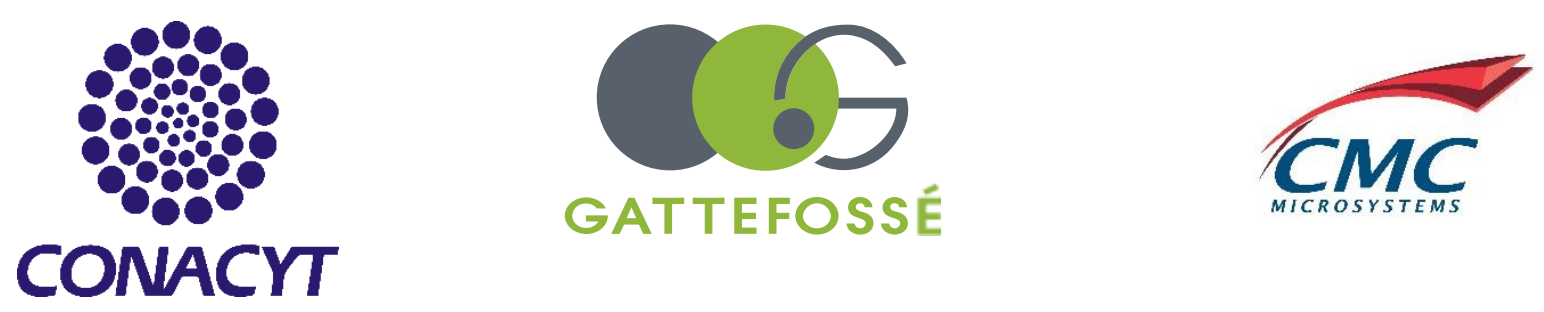

Nan○OAM

CONACYT 